\title{
Dependency of Purge Duration of an Atomic Layer Deposition Process on the Outlet Size of a Viscous Flow Reactor
}

\author{
Betelhiem N. Mengesha, Mohammad Reza Shaeri \\ Department of Mechanical Engineering, University of the District of Columbia, Washington, DC 20008, USA \\ betelhiem.mengesha@udc.edu; mohammadreza.shaeri@udc.edu
}

\begin{abstract}
For a better understanding the effects of size and number of outlet manifolds of a viscous flow reactor on the purge duration in an atomic layer deposition (ALD) process, three-dimensional multicomponent gas transports inside the reactors with different outlet configurations are investigated through reactor scale simulations. The simulations are performed at a fixed operating pressure and temperature of 10 torr $(1333 \mathrm{~Pa})$ and $300{ }^{\circ} \mathrm{C}$, respectively. Several reactor designs are considered and results are compared with a reactor that is used as the base of comparison. Because of low values of Knudsen numbers (less than 0.01) inside the reactors, applying the continuum flow assumption with no-slip boundary conditions is accurate to simulate the multicomponent flow. The Navier-Stokes and species transport equations are discretized through the finite volume method to simulate transient, laminar, and multicomponent flows. It is found that the purge durations are mainly dictated by the outlet velocity such that as long as the average outlet velocity remains the same, the purge times are almost similar among all reactors with different number of outlets. Also, results suggest that there is a threshold purge velocity such that beyond this value the purge times become independent from the outlet velocity.
\end{abstract}

Keywords: Atomic layer deposition; Viscous flow reactor; Purging; Multicomponent flow.

\section{Introduction}

Atomic layer deposition (ALD) is a key enabling nanotechnology to deposit ultrathin, highly conformal, and pinholefree angstrom-scale films on complex three-dimensional structures [1]-[3]. Such excellent characteristics have made ALD an attractive deposition technique in emerging applications such as semiconductor, energy conversion, fuel cells, membranes, solar cells, and batteries [4]-[6]. ALD is a cyclic process such that a binary reaction $a+b \rightarrow c+d$ is split into two selflimiting surface reactions by pulsing gaseous precursors of $a$ and $b$, alternatively, into the reactor with a purge between them [7]. An ALD cycle is divided into four steps and described by a timing sequence of $t_{1}-t_{2}-t_{3}-t_{4}$, as: (i) forming a new layer on the substrate due to the surface reactions at the first precursor exposure during $t_{1} \mathrm{~s}$, (ii) purging the reactor by an inert gas for $t_{2} \mathrm{~s}$, (iii) deposition of the desired film due to the surface reactions between the second precursor and the adsorbed species on the substrate during $t_{3} \mathrm{~s}$, and (iv) purging the reactor by an inert gas for $t_{4} \mathrm{~s}$ [8]-[10]. Purging is an essential step in an ALD process to prevent reactions between the two precursors and adverse impacts on the uniformity of the deposited films. Due to the self-limiting characteristic of surface reactions, the same thickness is deposited at the end of each cycle; therefore, the desired film thickness is simply obtained by repeating ALD cycles.

A reactor is a key component of an ALD process. Gaseous precursors and purge gas transport as well as surface reactions and film depositions take place inside the reactor. Among different kinds of reactors, viscous flow reactors with operating pressures between 1 and 10 torr (133-1333 Pa) have been widely used in a broad range of applications in different industries [7], [11]. However, despite their significant advantages such as deposition of highly conformal films, viscous flow reactors are prone to severe shortcoming of long operational times, which long purging is one of the reasons of such a slow process. As a result, any improvement that leads to a shorter ALD process without any penalty in the film quality will potentially save energy and reduce consumption of materials (i.e., precursors and purge gas).

Designing efficient reactors to improve the performance of ALD processes has been the subject of extensive research, particularly a series of studies by the author in [2], [9]. The objective of the present study is to investigate the effects of number and size of outlet manifolds as well as purge velocities on the duration of purging in an ALD process. This investigation is performed through a three-dimensional simulation of multicomponent flow inside the reactor. The present work is a supplement to the study by Shaeri et al. [9], which was demonstrated that a reactor with fewer outlets minimizes 
the ALD operational times. The previous study was performed for different outlet cross sections at only one purge velocity. The present work extends the study in [9] by investigating the effects of change in the number of outlet manifolds at a constant outlet cross section under a sufficiently wide range of purge velocities.

\section{Problem Description}

\subsection{Computational Model}

The conventionally used ALD viscous flow reactors include one inlet and one outlet manifold with substrates between two manifolds for deposition of films [9]. In this study, the purge durations within one ALD cycle in viscous flow reactors with different outlet configurations are compared with those in a conventional ALD reactor. The reactors are schematically shown in Fig. 1 . $D_{\text {in }}$ and $D_{\text {out }}$ correspond to the diameter of the inlet and outlet manifolds, respectively. The maximum number of outlets is two. The one-outlet reactor with $D_{\text {out }}=2 \mathrm{~mm}$ is used as the base of comparisons. The two-outlet reactors are studied at $D_{\text {out }}=2 \mathrm{~mm}$ and at two angular distances $(\theta)$ of $\theta=60^{\circ}$ and $\theta=120^{\circ}$. Also, another reactor with one outlet and $D_{\text {out }}=2.83 \mathrm{~mm}$, which has the same cross-sectional area as an average crosssectional area in two-outlet reactors is considered. In all reactors, $D_{\text {in }}=2 \mathrm{~mm}$.

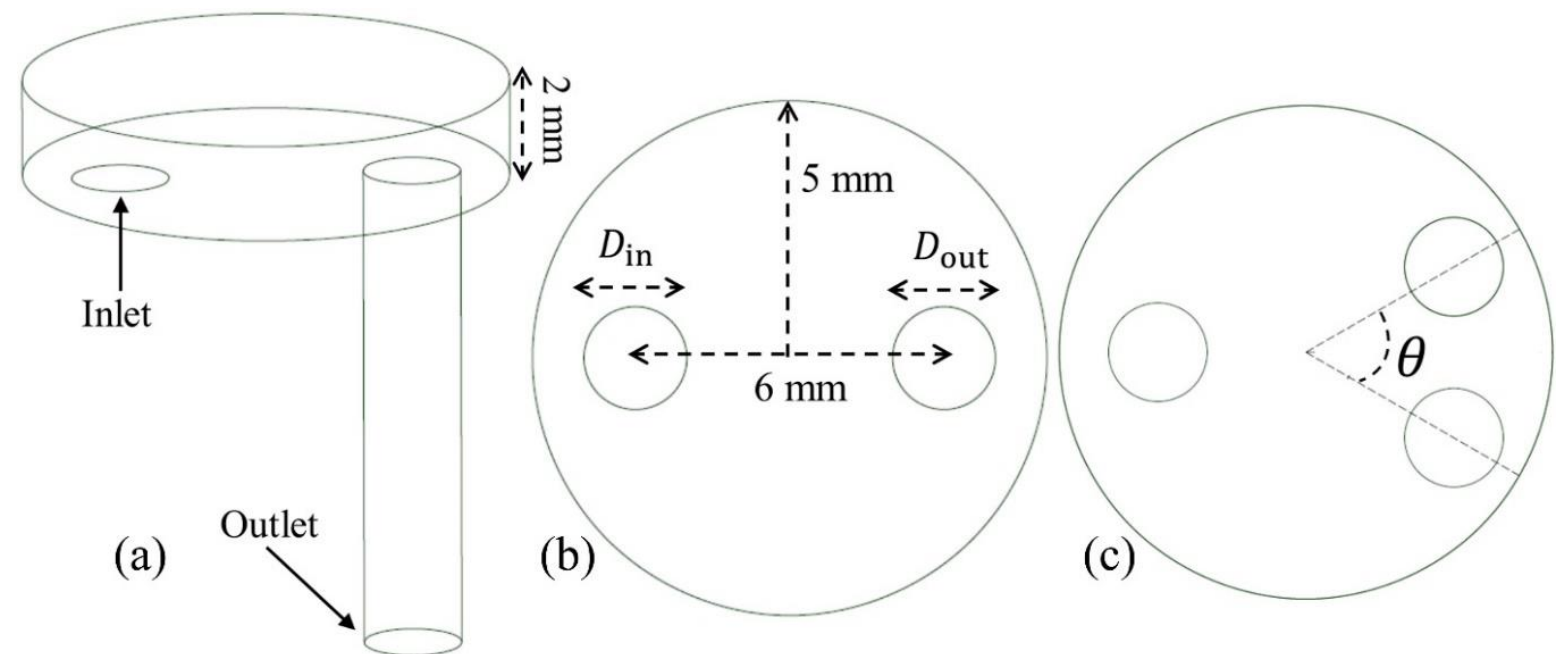

Fig. 1. (a) Three-dimensional view of the reactor; (b) Top view of the one-outlet reactor; (c) Top view of the two-outlet reactor.

To deposit an oxide film through an ALD process, one precursor is used as the metal source and another precursor is used as the oxygen source. In this study, the numerical procedure is described for deposition of $\mathrm{Al}_{2} \mathrm{O}_{3}$ from trimethylaluminum (TMA), $\mathrm{Al}\left(\mathrm{CH}_{3}\right)_{3}$, and ozone, $\mathrm{O}_{3}$, as the metal and oxygen sources, respectively, based on the global reaction $2 \mathrm{Al}\left(\mathrm{CH}_{3}\right)_{3}+\mathrm{O}_{3} \rightarrow \mathrm{Al}_{2} \mathrm{O}_{3}+3 \mathrm{C}_{2} \mathrm{H}_{6}$. Also, argon (Ar) is used as the purge gas. The reaction mechanism is retrieved from the previous research in [2], [9], and [12], as follows:

\begin{tabular}{|l|c|c|}
\hline TMA exposure & $\mathrm{Al}\left(\mathrm{CH}_{3}\right)_{3}+\mathrm{O}^{*} \rightarrow \mathrm{Al}\left(\mathrm{CH}_{3}\right)_{2}^{*}+0.5 \mathrm{C}_{2} \mathrm{H}_{6}$ & (1) \\
\hline \multirow{3}{*}{$\mathrm{O}_{3}$ exposure } & $\mathrm{O}_{3}+\mathrm{M} \rightleftarrows \mathrm{O}_{2}+\mathrm{O}+\mathrm{M}$ & $(2)$ \\
\cline { 2 - 3 } & $0+\mathrm{O}_{3} \rightleftarrows 2 \mathrm{O}_{2}$ & $(3)$ \\
\cline { 2 - 3 } & $2 \mathrm{Al}\left(\mathrm{CH}_{3}\right)_{2}^{*}+\mathrm{O} \rightarrow \mathrm{Al}\left(\mathrm{CH}_{3}\right) \mathrm{OAl}\left(\mathrm{CH}_{3}\right)^{*}+\mathrm{C}_{2} \mathrm{H}_{6}$ & $(4)$ \\
\cline { 2 - 3 } & $0.5 \mathrm{Al}\left(\mathrm{CH}_{3}\right) \mathrm{OAl}\left(\mathrm{CH}_{3}\right)^{*}+0 \rightarrow \mathrm{O}^{*}+0.5 \mathrm{C}_{2} \mathrm{H}_{6}+0.5\left(\mathrm{Al}_{2} \mathrm{O}_{3}\right)^{\mathrm{B}}$ & $(5)$ \\
\hline
\end{tabular}

where the asterisk and B superscripts represent surface and bulk species, respectively, and the remaining elements are gaseous species. The focus of this work is to investigate the effects of outlet manifolds on the purge duration. Because there are not any reactions during a purging process, the reactions and, in turn, film depositions are neglected in this 
study. As a result, only multicomponent flow transport is investigated inside the reactors. However, all products of the surface/gas-phase reactions will be considered in the reactors to maintain the purging process as close as possible to a real real ALD process. For this purpose, both precursor and products of reactions are pulsed into the reactor at each precursor exposure for filling the reactor volume with all gaseous species that are available during each precursor exposure. A timingtiming-sequence of 0.5-0.5-1-0.5 is used for the cycle, corresponding to (i) pulsing TMA and $\mathrm{C}_{2} \mathrm{H}_{6}$ for $0.5 \mathrm{~s}$, (ii) purging the the reactor with pure argon for $0.5 \mathrm{~s}$, (iii) pulsing $\mathrm{O}_{3}, \mathrm{O}_{2}, \mathrm{O}$, and $\mathrm{C}_{2} \mathrm{H}_{6}$ for $1 \mathrm{~s}$, and (iv) purging the reactor with pure argon for $0.5 \mathrm{~s}$. This timing sequence was obtained by several tests such that it is long enough to reach an equilibrium condition (unchanged mass fractions) in the reactor during the first and second precursor exposures and fill more than $99.9 \%$ of the reactor volumes by pure argon at both purge steps. The inlet conditions for the TMA and $\mathrm{C}_{2} \mathrm{H}_{6}$ exposures are $T=27^{\circ} \mathrm{C}$, $f_{\mathrm{TMA}}=f_{\mathrm{C}_{2} \mathrm{H}_{6}}=0.5$, and $V=0.6 \mathrm{~m} / \mathrm{s}$, where $T, f$, and $V$ are temperature, mole fraction, and velocity, respectively. The inlet conditions for $\mathrm{O}_{3}, \mathrm{O}_{2}, \mathrm{O}$, and $\mathrm{C}_{2} \mathrm{H}_{6}$ exposures are $T=27^{\circ} \mathrm{C}, f_{\mathrm{O}_{3}}=f_{\mathrm{O}_{2}}=f_{\mathrm{O}}=f_{\mathrm{C}_{2} \mathrm{H}_{6}}=0.25$, and $V=0.6 \mathrm{~m} / \mathrm{s}$. The inlet conditions for the purging are $T=27^{\circ} \mathrm{C}, f_{\mathrm{Ar}}=1.0$, and $V=V_{p}$, which $V_{p}$ represents the purge velocity. To have a better understanding about the performance of different reactors at different velocities, the simulations are performed at two purge velocities with a sufficiently large difference as $V_{p}=1.4 \mathrm{~m} / \mathrm{s}$ and $V_{p}=4.2 \mathrm{~m} / \mathrm{s}$. Zero axial gradients for all the variables are applied at the outlet. The remaining surfaces are walls at a fixed temperature and no-slip boundary conditions and zero diffusive mass fluxes normal to the surfaces. The simulations are performed for a fixed operating pressure and temperature of 10 torr $(1333 \mathrm{~Pa})$ and $300{ }^{\circ} \mathrm{C}$, respectively.

\subsection{Numerical Procedure}

The governing equations are transient continuity, momentum, energy, and species transport equations, which are discretized spatially and temporally using the second order upwind and the first order implicit methods, respectively, through the finite volume approach. In the previous studies by the author, it was demonstrated that the maximum Knudsen number inside the reactor is less than 0.01 [9]; thus, applying the continuum flow assumption with no-slip boundary conditions is accurate to simulate flow fields inside the reactors. The PISO algorithm is used to couple the pressure and velocity components. Ansys Fluent is used to solve the transport equations. A user defined function (UDF) is developed to change the inlet boundary conditions at each time-step. The detailed explanations about the governing equations as well as the parameters required for simulation of the multicomponent flow inside the reactors were provided in [12] and are omitted here for brevity. A grid structure with an element size of $0.35 \mathrm{~mm}$ and a time-step size of $0.01 \mathrm{~s}$ are selected for the simulations after performing several tests and reaching negligible changes (below 1.5\%) in the magnitudes of friction coefficient at the bottom surface of the reactor by further increase in the number of cells and decrease in the time-step size.

\section{Results}

Because an ALD process consists of several similar cycles, the present simulations are performed for only one cycle to save the computational time. The chemistry mechanism behind an ALD process is very complex and still is not well understood due to existences of many intermediates and elementary reactions. However, a quantitative prediction of the duration of an ALD cycle is not the focus of this study. Instead, the present study provides qualitative information about the effects of outlet cross-sectional area on purge durations, which will be beneficial to design optimized viscous flow reactors to reduce the overall operational time of an ALD process. Fig. 2 illustrates the mass fractions of all gaseous species inside the reactor throughout one cycle (i.e., $2.5 \mathrm{~s}$ ). During the first precursor injection, TMA and $\mathrm{C}_{2} \mathrm{H}_{6}$ are pulsed into the reactor and immediately reach an equilibrium condition (unchanged mass fractions) inside the reactor. The same condition happens during $\mathrm{O}_{3}, \mathrm{O}_{2}, \mathrm{O}$, and $\mathrm{C}_{2} \mathrm{H}_{6}$ exposure in the second precursor injection. When the purge gas (Ar) is pulsed into the reactor, it removes the remaining gases from the previous precursor injection until the entire reactor is completely filled with Ar. Since an ALD duration is mainly dictated by the purging process, the focus of the present study is on the mass fraction of argon during the purging steps. 


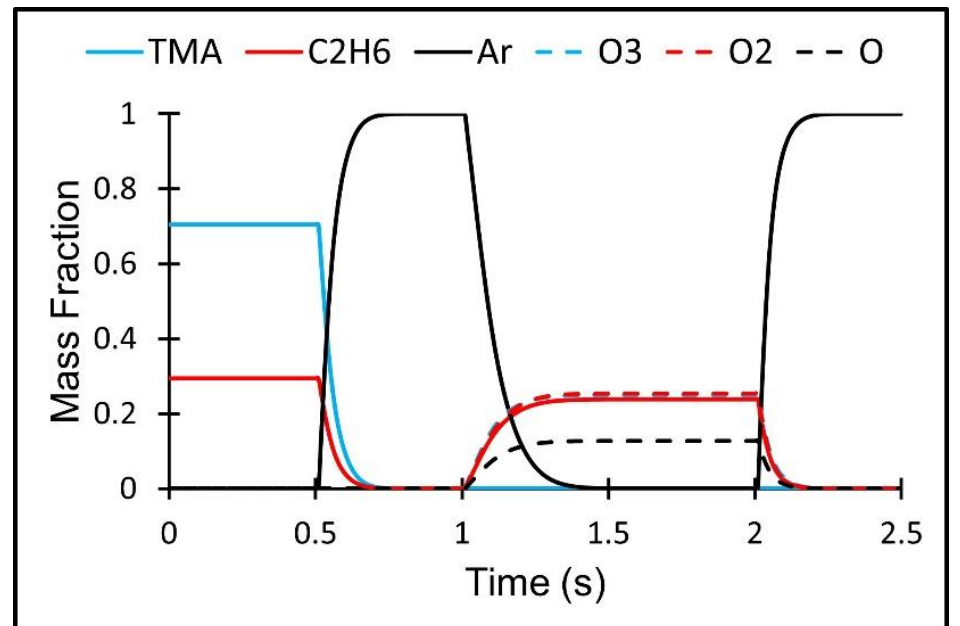

Fig. 2. Mass fractions of all gaseous species inside the one-outlet reactor during one ALD cycle. $D_{\text {out }}=2 \mathrm{~mm}$ and $V_{p}=1.4 \mathrm{~m} / \mathrm{s}$.

A shorter purging corresponds to reaching the mass fraction of Ar to unity inside the reactor in a faster time period and is identified by a sharper slope of the curve for the mass faction of Ar versus time during the purge step. A shorter purging is expected by increasing the purge velocity, as it is shown in Fig. 3 by comparison between the first and second purge times for a given reactor at two different velocities.

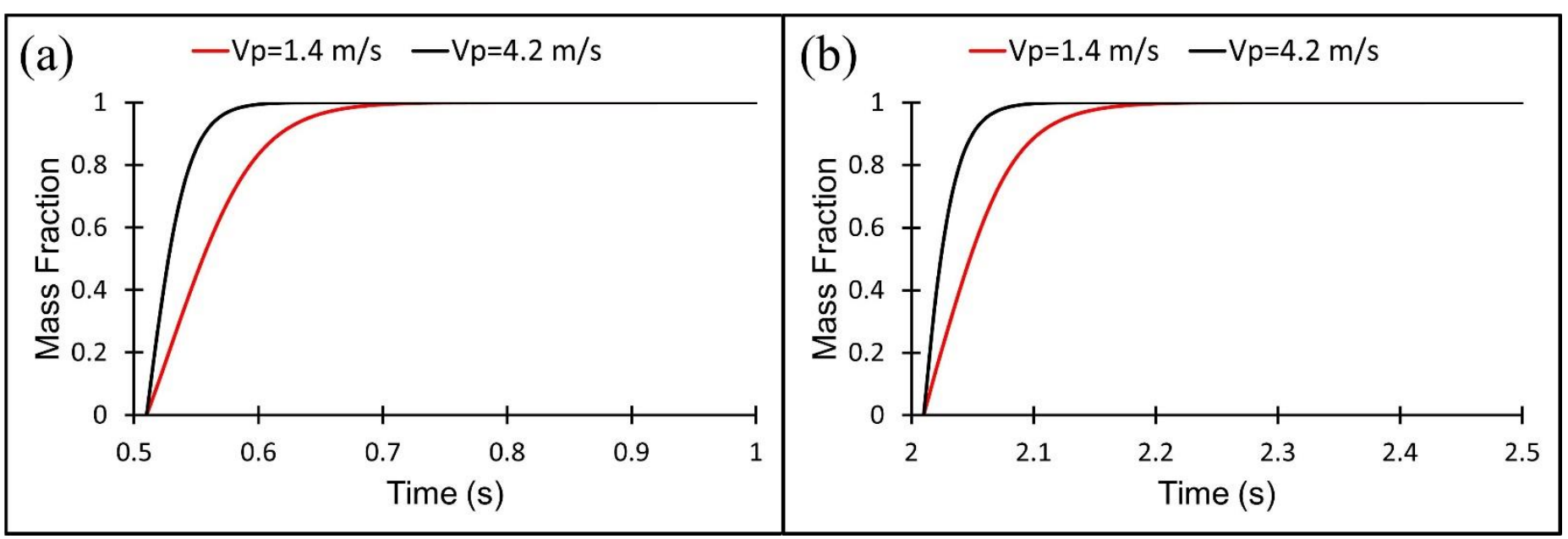

Fig. 3. Ar mass fraction at different purge velocities inside the reactor with two outlets and $\theta=60^{\circ}$. (a) First purge; (b) Second purge.

Figs. 4 and 5 illustrate the effects of changes in the outlet surface area at two different velocities on purge times. At low purge velocity $\left(V_{p}=1.4 \mathrm{~m} / \mathrm{s}\right)$, the purge durations are slightly shorter in one-outlet reactor while the durations are almost the same at high purge velocity $\left(V_{p}=4.2 \mathrm{~m} / \mathrm{s}\right)$. Since the inlet mass flow rate is the same among all the reactors, an increase in the number of outlet manifolds corresponds to an increase in the overall outlet surface area and in turn, a decrease in the outlet velocity, based on the continuity equation. Therefore, Fig. 4 indicates a dependency of purge times to outlet velocity. Since the outlet surface area and outlet velocities remain unchanged in two-outlet reactors, purge times are almost the same in these two reactors. However, Fig. 5 suggests that there may be a threshold purge velocity, which beyond that, the purge times are almost independent of the outlet velocities. This claim is further justified by Figs. 6 and 7 that show the shorter purge times due to a higher outlet velocity in a low purge velocity, and an independency of purge times to outlet velocity at a high purge velocity in one-outlet reactors with different outlet cross sections. 


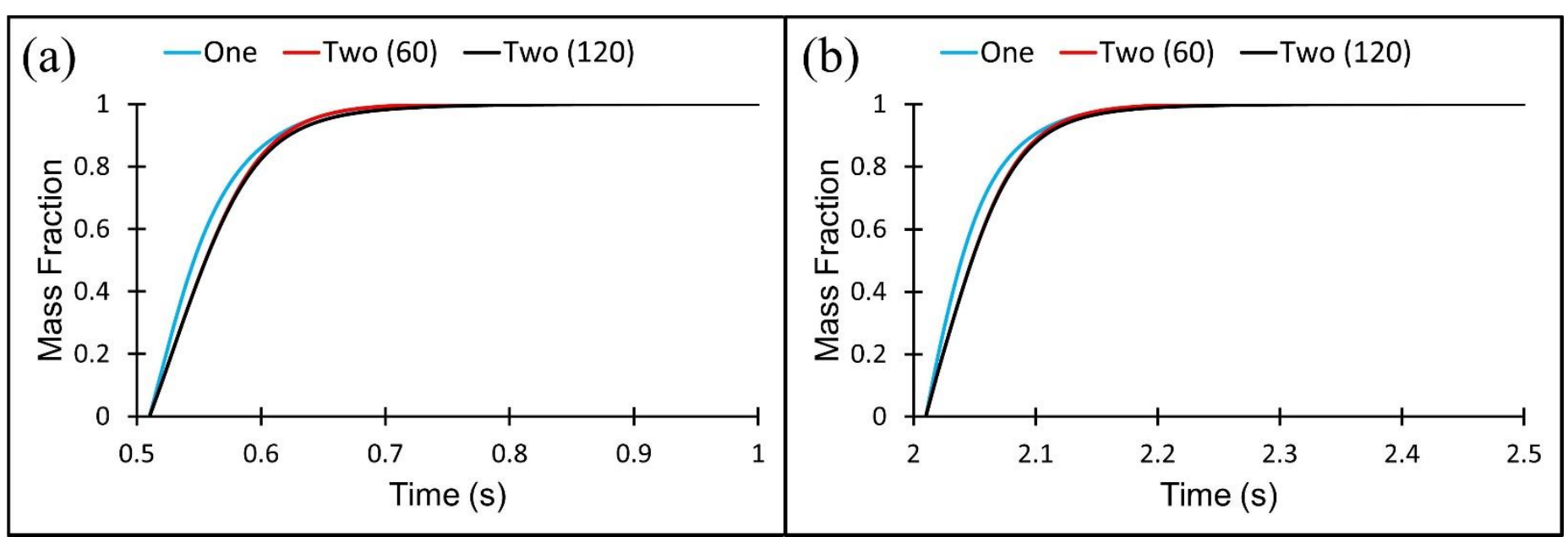

Fig. 4. Ar mass fraction inside the one- and two-outlet reactors with the same outlet diameter $\left(D_{\text {out }}=2 \mathrm{~mm}\right)$ at $V_{p}=1.4 \mathrm{~m} / \mathrm{s}$. The number inside the parentheses corresponds to the angle between outlet manifolds. (a) First purge; (b) Second purge.

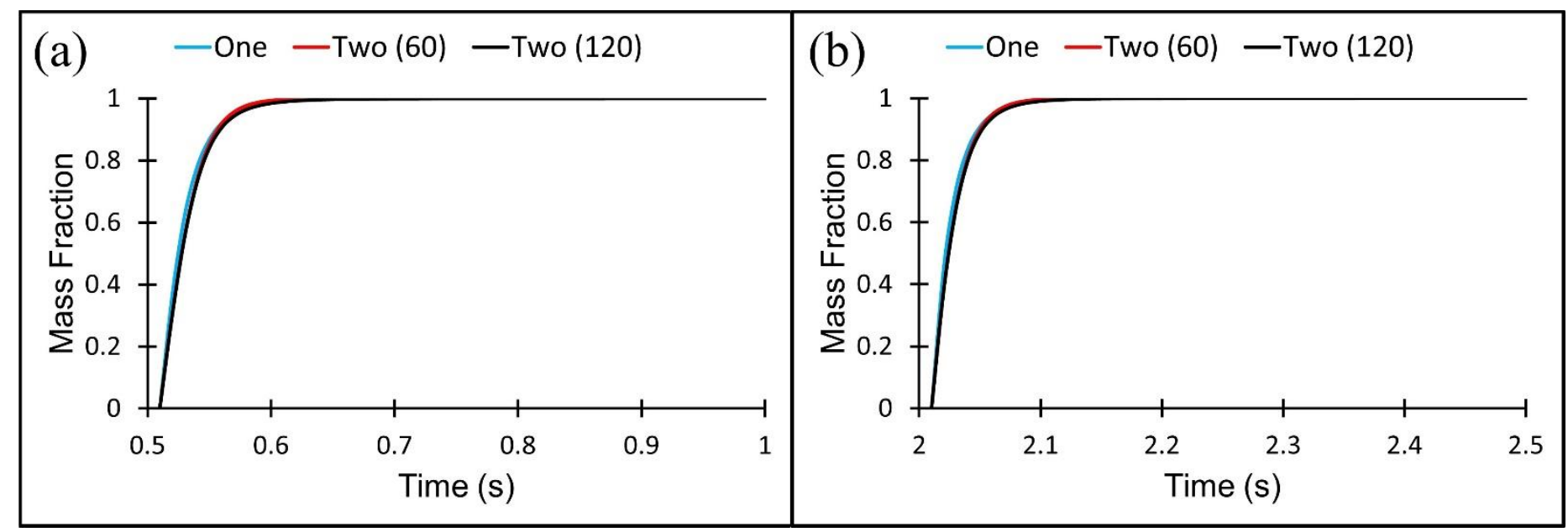

Fig. 5. Ar mass fraction inside the one- and two-outlet reactors with the same outlet diameter $\left(D_{\text {out }}=2 \mathrm{~mm}\right)$ at $V_{p}=4.2 \mathrm{~m} / \mathrm{s}$. The number inside the parentheses corresponds to the angle between outlet manifolds. (a) First purge; (b) Second purge.

The effects of purge velocities on the purge durations at a constant outlet surface area are shown in Figs. 8 and 9. An interesting conclusion from these two figures is that the purge duration is a strong function of the average outlet velocity such that as long as the average surface area at the outlet remains constant, purge times are independent from the number of outlet manifolds. This finding indicates the strong dependency of the purge times to outlet velocities, as it was obtained earlier. In addition, it is found that the purge times are almost independent from angular distances between the outlet manifolds in all reactor designs considered in this study. 


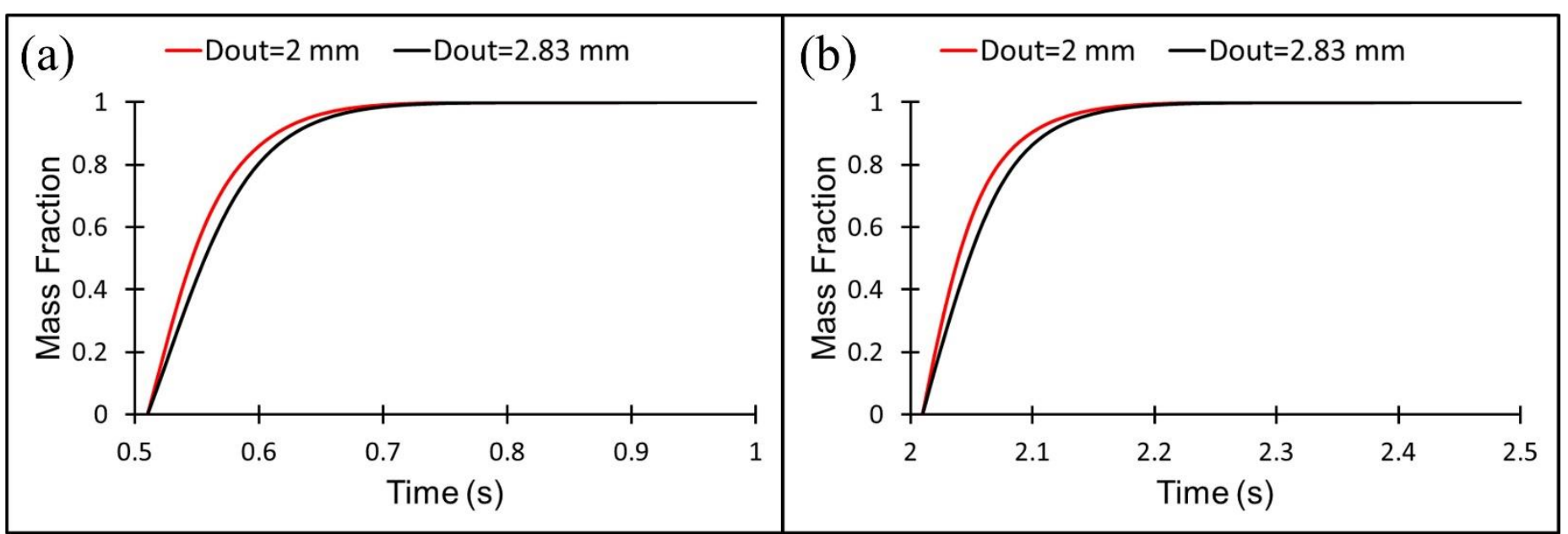

Fig. 6. Ar mass fraction inside the one-outlet reactors with different outlet diameter at $V_{p}=1.4 \mathrm{~m} / \mathrm{s}$. (a) First purge; (b) Second purge.

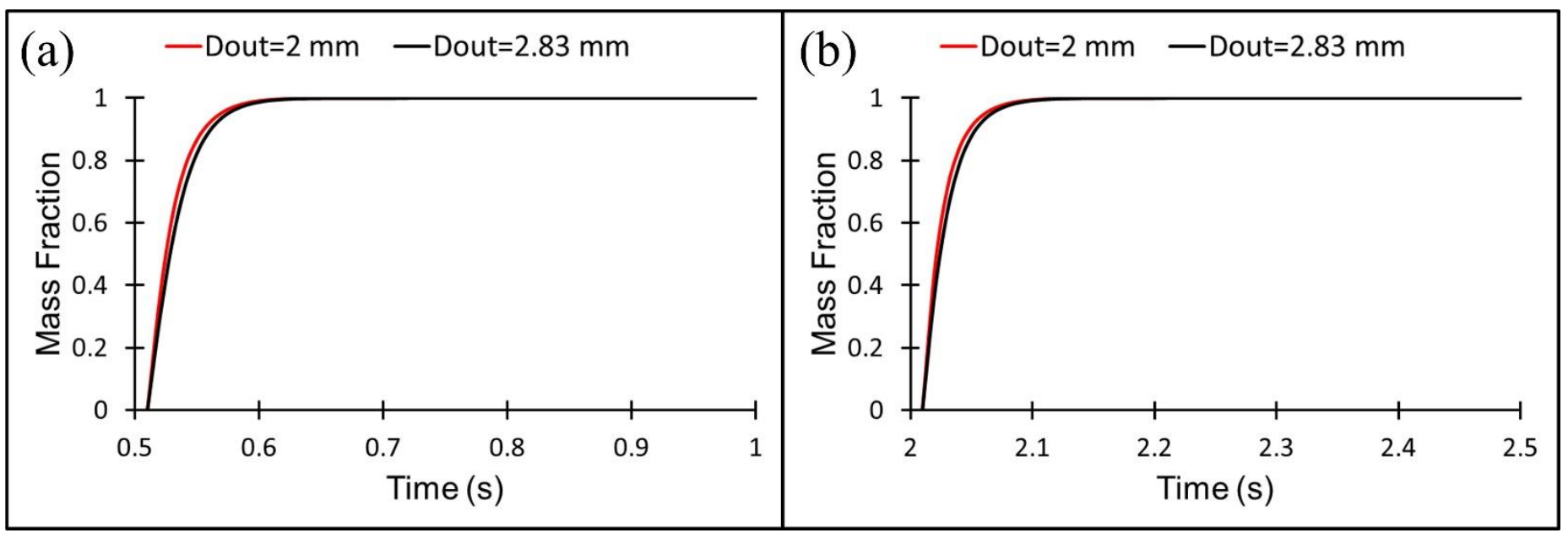

Fig. 7. Ar mass fraction inside the one-outlet reactors with different outlet diameter at $V_{p}=4.2 \mathrm{~m} / \mathrm{s}$. (a) First purge; (b) Second purge.

Although this study provides a preliminary understanding about the effects of outlet size/number on purge duration, further detailed research is required to supplement this work. It is important to extend the current research by considering a wider range of design parameters, e.g., size and number of outlets as well as overall size of the reactor. Also, further research is needed to identify the threshold purge velocity, which beyond that, purge times become independent from the outlet velocity. Because the threshold purge velocity depends on reactor design parameters, this dependency also should be clearly addressed. 


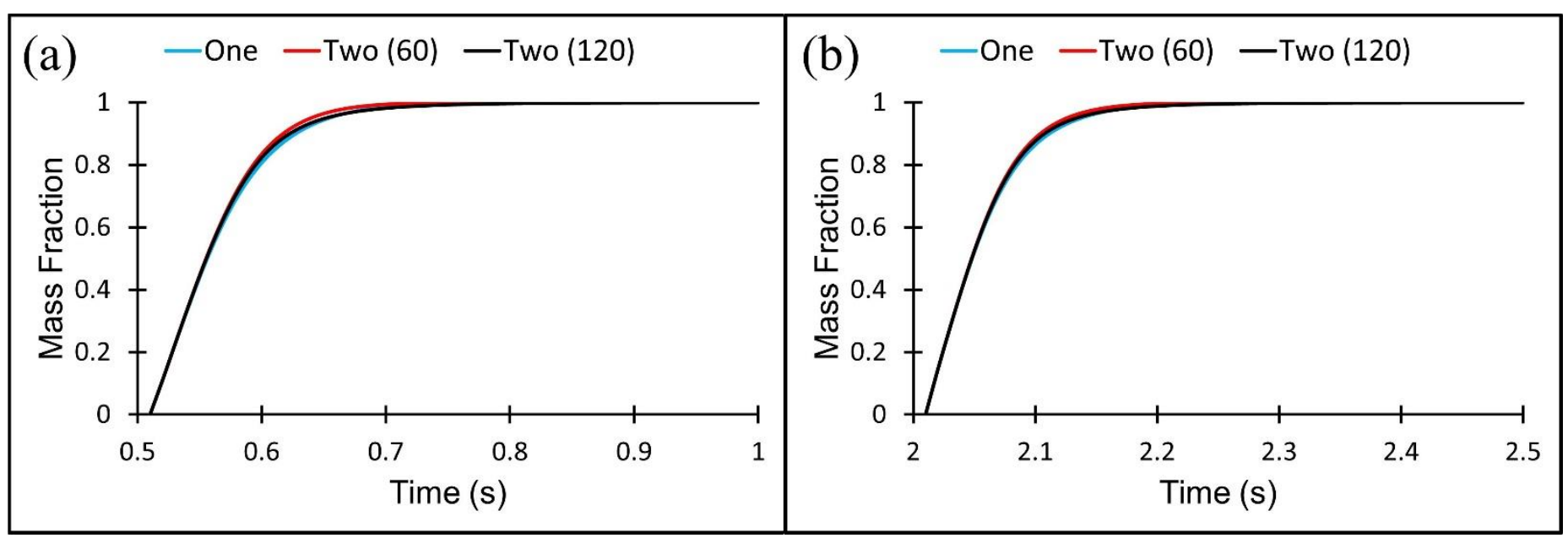

Fig. 8. Ar mass fraction inside the one- and two-outlet reactors with the same outlet cross-sectional area at $V_{p}=1.4 \mathrm{~m} / \mathrm{s}$. The number inside the parentheses corresponds to the angle between outlet manifolds. (a) First purge; (b) Second purge.

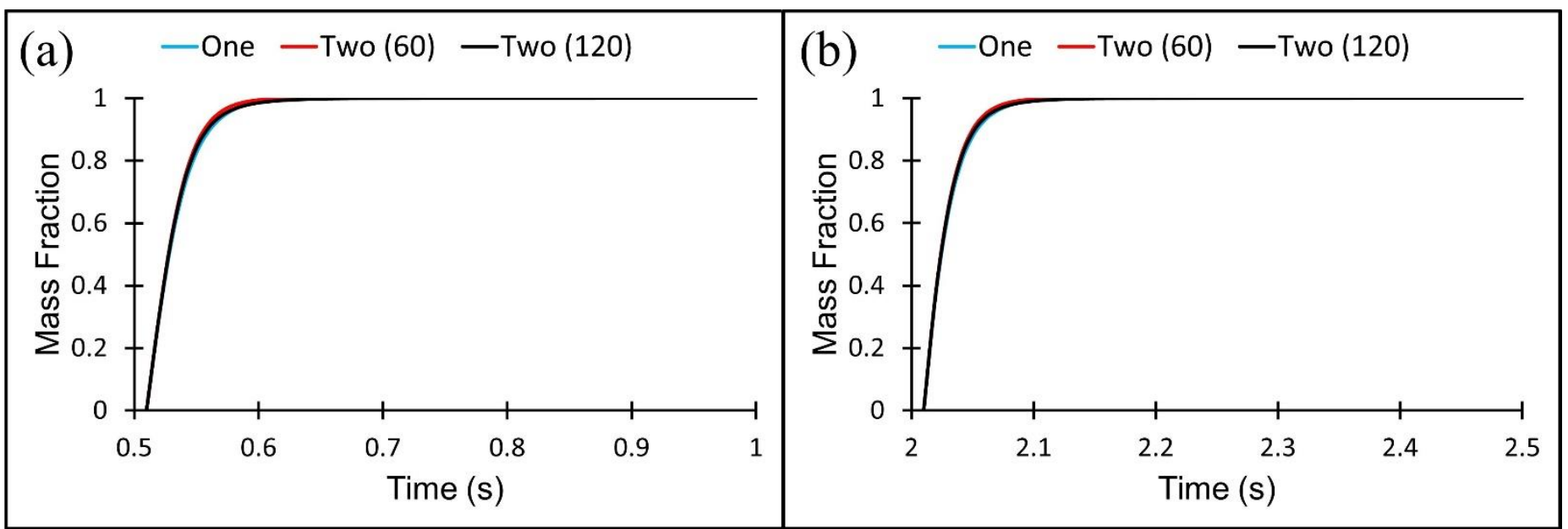

Fig. 9. Ar mass fraction inside the one- and two-outlet reactors with the same outlet cross-sectional area at $V_{p}=4.2 \mathrm{~m} / \mathrm{s}$. The number inside the parentheses corresponds to the angle between outlet manifolds. (a) First purge; (b) Second purge.

\section{Conclusion}

Three-dimensional simulations of multicomponent gas transport inside viscous flow reactors were performed to understand the effects of outlet cross-sectional area on the purge durations in an ALD process. Average outlet velocity was found as the main parameters to influence purge times. As long as the average outlet velocity in a multi-outlet reactor is equal to that of a one-outlet reactor, the purge durations were almost similar, which signified the negligible effects of the number of outlets on the purge durations in the multi-outlet reactor. The existence of a threshold purge velocity, which beyond that, the purge durations become independent from the outlet velocity was demonstrated. Suggestions for extending the present study were provided.

\section{Acknowledgements}

This research is supported by the National Science Foundation-CREST Award (Contract \# HRD-1914751) and the Department of Energy/National Nuclear Security Agency (DE-FOA-0003945). 


\section{References}

[1] C. Yang, Y. Zhang, F. Xiong, Y. Sun, "Photocorrosion of CdS nanorod arrays and fabrication of CdS@TiO 2 core@ shell nanorod arrays by atomic layer deposition for improved photostability," Opt. Mater.: X, vol. 9, pp. 100070, 2021.

[2] M. R. Shaeri, T. C. Jen, C. Y. Yuan, "Improving atomic layer deposition process through reactor scale simulation," Int. J. Heat Mass Transfer, vol. 78, pp. 1243-1253, 2014.

[3] M. Broas, O. Kanninen, V. Vuorinen, M. Tilli, M. Paulasto-Krockel, "Chemically stable atomic-layer-deposited $\mathrm{Al}_{2} \mathrm{O}_{3}$ films for processability,” ACS Omega, vol. 2, pp. 3390-3398, 2017.

[4] O. Graniel, M. Weber, S. Balme, P. Miele, M. Bechelany, "Atomic layer deposition for biosensing applications," Biosens. Bioelectron., vol. 122, pp. 147-159, 2018.

[5] S. Zhu, J. Liu, J. Sun, "Growth of ultrathin $\mathrm{SnO}_{2}$ on carbon nanotubes by atomic layer deposition and their application in lithium ion battery anodes," Appl. Surf. Sci., vol. 484, pp. 600-609, 2019.

[6] R. W. Johnson, A. Hultqvist, S. F. Bent, "A brief review of atomic layer deposition: from fundamentals to applications," Mater. Today, vol. 17, pp. 236-246, 2014.

[7] M. R. Shaeri, D. Guan, F. Cao, C. Y. Yuan, "Developing high-temperature water-repellent glass fiber cloths through atomic layer deposition," ASTFE Digital Library. Begel House Inc., pp. 849-852, 2018.

[8] P. O. Oviroh, R. Akbarzadeh, D. Pan, R. A. M. Coetzee, T. C. Jen, "New development of atomic layer deposition: processes, methods and applications," Sci. Technol. Adv. Mater., vol. 20, pp. 465-496, 2019.

[9] M. R. Shaeri, T. C. Jen, C. Y. Yuan, M. Behnia, "Investigating atomic layer deposition characteristics in multi-outlet viscous flow reactors through reactor scale simulations," Int. J. Heat Mass Transfer, vol. 89, pp. 468-481, 2015

[10] S. C. Riha, A. A. Koegel, X. Meng, I. S. Kim, Y. Cao, M. J. Pellin, J. W. Elam, A. B. F. Martinson, "Atomic layer deposition of MnS: phase control and electrochemical applications," ACS Appl. Mater. Interfaces, vol. 8, pp. 27742780, 2016.

[11] M. Schuisky, J. W. Elam, S. M. George, "In situ resistivity measurements during the atomic layer deposition of ZnO and W thin films," Appl. Phys. Lett., vol. 81, pp. 180-182, 2002.

[12] M. R. Shaeri, T. C. Jen, C. Y. Yuan, "Reactor scale simulation of an atomic layer deposition process," Chem. Eng. Res. Des., vol. 94, pp. 584-593, 2015. 